University of Nebraska - Lincoln

DigitalCommons@University of Nebraska - Lincoln

Faculty Publications, Department of Child, Youth, and Family Studies

Child, Youth, and Family Studies, Department of

$6-2016$

\title{
Child and Parent Report of Parenting as Predictors of Substance Use and Suspensions from School
}

\author{
Charles B. Fleming \\ University of Washington, cnbflem@uw.edu \\ W. Alex Mason \\ National Research Institute for Child and Family Studies \\ Ronald W. Thompson \\ National Research Institute for Child and Family Studies \\ Kevin P. Haggerty \\ University of Washington \\ Thomas Jai. Gross \\ University of Nebraska-Lincoln
}

Follow this and additional works at: https://digitalcommons.unl.edu/famconfacpub

Part of the Developmental Psychology Commons, Family, Life Course, and Society Commons, Other Psychology Commons, and the Other Sociology Commons

Fleming, Charles B.; Mason, W. Alex; Thompson, Ronald W.; Haggerty, Kevin P.; and Gross, Thomas Jai., "Child and Parent Report of Parenting as Predictors of Substance Use and Suspensions from School" (2016). Faculty Publications, Department of Child, Youth, and Family Studies. 168.

https://digitalcommons.unl.edu/famconfacpub/168

This Article is brought to you for free and open access by the Child, Youth, and Family Studies, Department of at DigitalCommons@University of Nebraska - Lincoln. It has been accepted for inclusion in Faculty Publications, Department of Child, Youth, and Family Studies by an authorized administrator of DigitalCommons@University of Nebraska - Lincoln. 
Published in final edited form as:

J Early Adolesc. 2016 June ; 36(5): 625-645. doi:10.1177/0272431615574886.

PMCID: PMC4968695 Copyright (c) 2016 SAGE Publications. Used by permission.

\section{Child and Parent Report of Parenting as Predictors of Substance Use and Suspensions from School}

\section{Charles B. Fleming,}

Social Development Research Group, School of Social Work, University of Washington, 9725 3rd Ave. NE, Suite 401, Seattle, WA 98115; phone: 206-685-8497, fax: 206-543-4507

\section{W. Alex Mason,}

National Research Institute for Child and Family Studies, Boys Town

\section{Ronald W. Thompson,}

National Research Institute for Child and Family Studies, Boys Town

Kevin P. Haggerty, and

Social Development Research Group, School of Social Work, University of Washington, 9725 3rd Ave. NE, Suite 401, Seattle, WA 98115

\section{Thomas Jai. Gross}

Center for Child and Family Well Being, University of Nebraska - Lincoln

Charles B. Fleming: cnbflem@uw.edu

\section{Abstract}

This study examined how child and parent reports of parenting were related to early adolescent substance use and school suspensions. Data were from two time points six months apart on 321 families with an eighth grade student attending one of five schools in the Pacific Northwest. Childand parent-report measures of family management practices were moderately correlated $(r=.29)$. Child report, but not parent report, of more positive family management practices uniquely predicted a lower likelihood of adolescent substance use. Also, discrepancies between child and parent report of parenting predicted substance use, with child positive report of family management losing its protective association with adolescent substance use when parents had negative reports of their parenting. Parent report, but not child report, of better parenting predicted lower likelihood of suspensions, suggesting that the salience of child and parent report may depend on the type of behavioral outcome.

\section{Keywords}

Early adolescence; Substance use; School suspensions; Parenting; Informant discrepancies; Multiple informants

Researchers commonly measure parenting practices based on child and parent reports, which often diverge (Jacob \& Windle, 1999; Laird \& De Los Reyes, 2013; Pasch, Stigler, Perry, \& Komro, 2010). This divergence may reflect differences in perspective and salience with respect to different behavioral outcomes (De Los Reyes, Thomas, Goodman, \& Kundey, 2013; Hoeve et al., 2009; Pasch et al., 2010); in addition, the degree of divergence 
itself may be a meaningful predictor of child behavior (De Los Reyes, Goodman, Kliewer, \& Reid-Quinones, 2010; De Los Reyes et al., 2013; K. L. Goodman, De Los Reyes, \& Bradshaw, 2010). Prior research has had mixed findings for whether child or parent reports of parenting practices are better predictors of child behavior problems (Hoeve et al., 2009), and whether agreement between child and parent report of parenting is an important predictor of child outcomes (Laird \& De Los Reyes, 2013; Reynolds, MacPherson, Matusiewicz, Schreiber, \& Lejuez, 2011). The current study examines predictive associations between child and parent reports of parenting and two early adolescent behavioral outcomes: substance use and school suspensions.

\section{Child and Parent Report of Parenting}

Lower rates of child and adolescent problem behaviors has been linked to parenting practices that include use of appropriate positive and negative consequences for child behavior; warmth, involvement, and frequent communication; and effective monitoring or supervision (Fletcher, Steinberg, \& Williams-Wheeler, 2004; Keijsers, Branje, VanderValk, \& Meeus, 2010 ; Laird, Marrero, \& Sentse, 2010; Willoughby \& Hamza, 2010). These different practices characterize parenting styles that can be measured as a global family management construct (Baumrind, 1991; Patterson, DeBaryshe, \& Ramsey, 1989; Wolf, 1976). Assessment of family management practices is commonly derived from either child or parent report, or a combination of both reports. However, the correlation between childand parent-derived measures of parenting is typically low $(I s<.3)$ even when the same survey questions (with minor changes in wording) are posed to both children and their parents (Jacob \& Windle, 1999; Pasch et al., 2010).

De Los Reyes and colleagues (2013) provide a framework, called the Operations Triad Model, for using measures of a construct that are derived from different reporters and diverge. A common approach is to treat discrepancies between reporters as the result of measurement error. If measurement error is equal across reporters, findings for prediction of child outcomes should be consistent and converge. This Converging Operations scenario supports the practice of combining child and parent report into one scale or as indicators of a latent construct. In some instance, however, multiple reporters may offer substantively different information due to differences in perspectives. De Los Reyes et al. classify this situation as Diverging Operations, which covers instances where measures derived from different reporters may have independent, unique associations with outcomes; furthermore, the degree of divergence itself may be associated with outcomes (K. L. Goodman et al., 2010).

Unique child and parent perspectives may have differential salience with respect to predicting various child behavioral outcomes. Child reports may be more telling for dimensions of parenting involving negative practices that reflect poorly on parents and on which parents may be hesitant to report accurately (Hoeve et al., 2009). Also, child report of parenting offers more information on the child's perception of parental warmth and control, which may be a more proximal and stronger influence than actual parenting practices on behavioral choices (Catalano \& Hawkins, 1996; Fletcher et al., 2004). Finally, if children engage in covert behaviors, they may also deceive their parents about those aspects of family 
management in which children have some agency. That is, children should be better reporters of components of parenting practices that are child driven. Kerr and colleagues (Kerr \& Stattin, 2000; Kerr, Stattin, \& Burk, 2010) have argued that most measures of parental monitoring are capturing parent knowledge that is largely a function of what children choose to disclose to their parents. Kerr and colleagues also argue that child disclosure is associated with child delinquency and drives the relationships between measures of monitoring and delinquency. This dynamic could be particularly relevant in cases where measures of covert behaviors depend on child self-report and measured associations could be influenced by shared method variance, for instance, as children who admit to covert antisocial behaviors may also be willing to give negative reports of their parents' family management practices. Parents, however, may be better reporters of family processes that are more parent driven (De Los Reyes et al., 2010). For instance, parents may report more accurately on their efforts to supervise behavior, solicit information from their children, and give appropriate consequences. If these practices are truly influential, we might find parent reports to be more predictive of child behavioral outcomes.

Evidence for whether child or parent report of parenting is more strongly associated with child behavioral outcomes tends to favor child report. In examining parenting practices as predictors of adolescent behavior, many researchers have chosen an analysis strategy based on what De Los Reyes and colleagues (2013) term Compensating Operations, relying on child report of parenting, under the assumption that child perceptions of family management are more important than what parents are actually doing (Hawkins, Catalano, \& Miller, 1992; Hill, Hawkins, Catalano, Abbott, \& Guo, 2005; Kosterman, Hawkins, Guo, Catalano, \& Abbott, 2000; Mason \& Windle, 2001). Kerr and colleagues (2010), focusing on the interrelationships between child disclosure, parent monitoring, and parent knowledge, found that both parent and child report of disclosure predicted parent knowledge and delinquency, although they did not test parent and child report as predictors in the same model. In a study that included parallel child and parent report measures, Laird and colleagues (2010) found that child report of parenting practices more strongly predicted antisocial behavior. In a meta-analysis of studies on parenting and delinquency, Hoeve and colleagues (2009) found that associations between authoritarian parenting (e.g., use of harsh discipline such as physical punishment and yelling) and delinquency were stronger when parenting measures came from child report. Hoeve et al., however, did not find that the strength of associations between delinquency and other dimensions of parenting differed by the source of reporting on parenting. Pasch and colleagues (2010) found that both child and parent reports uniquely predicted early adolescent alcohol use, with child reports of more alcohol-specific communication and parent report of more parental monitoring associated with less alcohol use. This finding of independent, unique effects for both child and parent report of aspects of parenting would suggest that meaningful and separate predictive power may come from both child and parent report.

Whether one perspective is a better predictor than the other may depend on the outcome being predicted. An important characteristic of the outcome may be whether the behavior is covert or overt (Loeber \& Schmaling, 1985) and the extent to which it is visible or known to parents. In the current study, we examine prediction of substance use and school suspensions. Although these two outcomes are likely related (Hemphill et al., 2011), they 
can differ in the degree to which they are hidden from parents. Adolescent substance use, particularly in early adolescence, frequently takes place without parents' knowledge and without the adolescent getting caught (Morleo, Cook, Elliott, \& Phillips-Howard, 2013). Thus, substance use often is closer to the covert end of the covert-overt spectrum of antisocial behavior (Loeber and Schmaling (1985)) and may be more closely related to the child's perspective on family management.

Although it is possible that parents might not know if their child is suspended from school, usually schools, if not the children, will inform parents of suspensions. School suspensions are meant to punish an inappropriate behavior that occurs within the school environment (Mendez \& Knoff, 2003). Often school administrators are attempting to decrease overt antisocial behaviors, such as conflicts with other students or teachers, but may also punish behaviors such as theft, cheating, or substance abuse, for which a student gets caught. School suspensions and expulsions, particularly for African American males, have been identified as part of a "school-to-prison pipeline" (Losen \& Skiba, 2010; Skiba et al., 2011), with out-of-school suspension during early adolescence a common event in a life course characterized later by high school dropout, arrests, and incarceration. Although there has been little research on the association between family processes and school suspensions, family management may influence adolescent involvement in the types of oppositional or rule-breaking behaviors for which adolescents get caught and which may result in school suspensions.

\section{Discrepancy as a Predictor of Outcomes}

In instances of Diverging Operations, where separate and meaningful information comes from different reports on the same construct, it may be that the discrepancy itself predicts behavioral outcomes (De Los Reyes et al., 2010; K. L. Goodman et al., 2010; Reynolds et al., 2011). Discrepancies may tap into aspects of the parent-child relationship that are predictive of child behavior, above and beyond the additive effects of the two different perspectives. As suggested by Goodman and colleagues (2010), when parents and children agree and perceive family processes similarly, it may be an indicator of better underlying functioning of the parent-child relationship. Conversely, discrepancies may reveal disharmony or lack of disclosure that is not captured by either parent or child report alone or by the average or sum of the two perspectives (see also De Los Reyes et al., 2010). Discrepancy effects can be seen as a form of moderation in that, say, the protective association of one report of positive family management is contingent on the other reporter also giving a positive report of parenting practices (Laird \& De Los Reyes, 2013).

Some research supports a Diverging Operations model of discrepancy having associations with child behavior over and above the main effects of either child- or parent-report measures. With respect to measures of parenting, De Los Reyes and colleagues (2010) found that parent-child discrepancies in reports of parental monitoring predicted more early adolescent delinquency, and Reynolds and colleagues (2011) found that parent-child discrepancies in reports of parent knowledge were positively associated with a composite measure of risk-taking behaviors including substance use, fighting, gambling, and theft. 


\section{Current Study}

The current study uses longitudinal data on an urban sample of eighth graders to examine how child- and parent-report measures of parenting are related to substance use and suspensions. We test whether child or parent reports, when considered together, predict substance use and suspensions, assessing whether child or parent perspectives are salient, as well as the possibility that prediction might differ across the two outcomes. We also examine discrepancies between child and parent reports as a predictor of outcomes, testing whether discrepancies are related to adverse behaviors or outcomes over and above the levels of family management reported by either children or their parents.

\section{Method}

\section{Sample and Procedures}

Data are from families enrolled in a randomized controlled trial of the Common Sense Parenting (CSP) intervention. The trial involved a collaboration between researchers at the University of Washington and Father Flanagan's Boys' Home (Boys Town). CSP is a universal preventive intervention involving parent-training workshops that was developed at Boys Town (Burke, Schuchmann, \& Barnes, 2006). CSP is one of a continuum of family and community-based interventions that have been developed and tested at Boys Town in recent years. Each family in the study includes a target parent and a target eighth grader who attended one of five public middle schools in Tacoma, Washington. At all five schools, the proportion of students in Grades 6 through 8 who were receiving free or reduced-price school lunch was above $70 \%$ in the 2010/2011 school year. Three of the five schools fed into a high school with a 5-year graduation rate of 52\% for the class of 2010. Potential participants were informed of the project by research staff who presented the study during core classes and distributed permission-to-contact forms for the students to take home to their parents. Schools aided the recruitment effort by disseminating notices of the study (e.g., emails, automated phone reminders). Schools also mailed a copy of the permission-tocontact forms directly to families who had not responded to initial recruitment efforts.

Families were enrolled in the project in two cohorts. The total population of eighth-grade students in the three recruitment schools in the 1st year and the five recruitment schools in the 2 nd year consisted of 1,646 students. Permission slips agreeing to release of contact information were returned by 658 families (representing approximately $40 \%$ of eligible students). Of these families, 321 (49\%) were contacted, were determined eligible, and chose to enroll in the project, 122 families in the 2010/2011 school year and 199 families in 2011/2012. Of the families enrolled, 108 were assigned to a minimal contact control condition, 118 were in the standard six-session standard CSP program condition, and 95 were in the eight-session CSP Plus program condition that included two sessions in which children (i.e., eighth grade students) were invited to attend (Fleming et al., in press; Mason et al., in press). In the present study, based on preliminary analyses described below that found little evidence of differences across condition in family management practices or child outcomes, we included families from all three conditions in our analyses. All procedures were reviewed and approved by the University of Washington and Father Flanagan's Boys' 
Home (Boys Town) institutional review boards as well as the participating school district (see Mason et al., in press for more details).

The sample of 321 families was socioeconomically diverse, although most families were low income. According to parent self-report of race, the composition of the parent sample was 48\% Caucasian, 26\% African American, 4\% Asian American, 4\% Pacific Islander, 2\% Native American, 9\% Hispanic, and 7\% mixed or "other". Fourteen percent reported their ethnicity as Hispanic. Most of the parents (72\%) were the biological mothers of the eighthgrade students, while $14 \%$ were biological fathers and the remainder were stepparents, grandparents, or some other guardian. Eighty-three percent of the parents were female (e.g., biological mother, stepmother). Forty-six percent were married, $23 \%$ were in a committed relationship but not married, and 31\% were single; $60 \%$ reported living with a spouse or significant other. Parent average age was 40.21 years $(S D=7.49)$. Forty-two percent of the parents reported annual incomes below $\$ 24,000$ for their households and $59 \%$ received food stamps. Forty-four percent of the parents were employed full time, 15\% part time, and 13\% considered themselves unemployed while $28 \%$ categorized themselves as out of the workforce (e.g., student, homemaker or disabled). Ten percent of the parents had not completed high school, $57 \%$ were high school graduates or had a GED, $20 \%$ had completed an AA degree or some post-high school vocational/technical program, and 13\% had a Bachelor's or more advanced degree. The mean age at enrollment for the eighth-grade students in the study was 13.41 years $(S D=0.52)$, and $55 \%$ were female. Comparisons of the sample of students enrolled in the project with the population of eighth-grade families in participating schools based on district data revealed several similarities (e.g., sample/ population: free lunch $=78 \% / 80 \%$, student special education status $=17 \% / 15 \%$ ) and some generally small differences (e.g., sample/population: student female gender $=53 \% / 47 \%$ ). Eligibility criteria required that parents speak English to participate in the parenting workshops for the trial; thus, there was a lower rate of Hispanic participants compared to the population (sample/population: Hispanic $=14 \% / 23 \%$ ).

Parents and students completed baseline surveys when they enrolled and were asked to complete a survey approximately 6 months later. Both baseline and 6-month follow-up interviews took place in families' homes. Surveys were self-administered on laptop computers, with a data collection staff person present to provide assistance. In both years of the study, enrollment and baseline interviews began in November/December and were completed by April. Follow-up interviews began in May/June and were completed by September. Overall, 298 (93\%) of the families enrolled in the study were interviewed at follow-up. Follow-up completion rates did not differ by race, ethnicity, or whether families received food stamps. The completion rate for families of boys (97\%) was significantly higher than that for families of girls $(90 \%)\left(\chi^{2}(1)=6.22, p=.013\right)$. Parents who did not complete the follow-up interview were significantly older than those who did $(M=43.70$, $S D=9.58$, vs. $M=39.94, S D=7.25, t(317)=2.33, p=.020)$.

\section{Measures}

Child- and parent-report measures of family management were based on a composite of four scales from the Alabama Parenting Questionnaire (APQ). The parent involvement scale 
came from the original APQ (Frick, Christian, \& Wootton, 1999; Shelton, Frick, \& Wootton, 1996), while the other three scales were from the Short Form-APQ (Elgar, Waschbusch, Dadds, \& Sigvaldason, 2007). All items were asked of both parents and children with minor differences in wording. All items asked how often a given behavior typically occurs, with no time frame reference, and offered a 5-point response option ranging from $1=$ "Never" to $5=$ "Always." Scale scores were based on the mean of item scores. The parent involvement scale was based on 10 items (child-report $\alpha=.83$, parent-report $\alpha=.80$; example items: "How often have you had a friendly talk with your parent (child)?" and "How often have you played a game or did some other fun thing with your parent (child)?") and captures frequency of communication and parent involvement in activities with the child. Positive parenting was based on three items (child-report $\mathrm{\alpha}=.81$, parent-report $\mathrm{\alpha}=.81$; example: "How often does your parent (do you) let you (your child) know when you are (he/she is) doing a good job with something?") and measured how often the parent provided praise and recognition for prosocial behavior. Inconsistent discipline was based on three items (childreport $\alpha=.56$, parent-report $\alpha=.61$; example: "How often does your parent (do you) threaten to punish you (your child) and then does (do) not actually punish you (him/her)?") and measured the frequency with which parents fail to follow through with a consequence when the child misbehaves or breaks a family rule. Poor supervision consisted of three items related to parental knowledge and child disclosure (child-report $\alpha=.50$, parent-report $\alpha=$. 64; examples: "How often do you (does your child) go out with friends your parent doesn't (you don't) know?" and "How often do you (does your child) stay out in the evening past the time you are (he/she is) supposed to be home?"). As has been found in some other studies using the APQ (e.g., Elgar et al., 2007; Frick et al., 1999; Shelton et al., 1996), the internal consistencies of the latter two subscales were low, particularly for child report.

The APQ subscales were correlated within reporter in the expected direction. The strongest associations were between involvement and positive parenting (child-report $r=.60$, parentreport $r=.56)$. Absolute values of correlations among other dimensions of parenting within reporter ranged from $r=.11$ (parent reports of involvement and inconsistent discipline) to $r$ $=.35$ (child reports of inconsistent discipline and poor supervision). In the current study, we use a measure of positive family management based on the mean of $\mathrm{z}$ scores of the four parenting scales, with the inconsistent discipline and poor supervision subscales reverse coded so that higher scores reflect more positive and less negative parenting. The a for the combination of z-scores (treating each subscale z-score as one component in the scale) was . 62 for both the child- and parent-report measures.

\section{Adolescent behavior outcomes}

Suspensions was measured by child report at baseline and 6-month follow-up. The suspension item asked at baseline was: "During the past 12 months, how many times have you been suspended from school for disciplinary reasons?" At 6-month follow-up, the item was: "Since the last interview, how many times have you been suspended from school for disciplinary reasons?" Items were coded to $0=$ never, $1=$ once or more. At baseline, $25 \%$ of students reported a suspension in the prior year while $19 \%$ reported a suspension between baseline and follow-up. 
Substance use was represented by dichotomous measures at baseline and follow-up based on child survey questions concerning cigarette and cigar smoking, smokeless tobacco use, alcohol use, and marijuana use. The time frame for the substance use items was "ever" at baseline and "since the last interview" at follow-up. Measures were coded so that $0=$ no use and $1=$ some use, which captured the primary source of variance in substance use, since few participants at the end of eighth grade reported frequent substance use. At baseline, 27\% reported initiating substance use; at follow-up, $17 \%$ reported substance use since baseline interview.

\section{Covariates}

Covariates were included in the analyses predicting substance use and suspensions to account for the fact that both family management, substance use, and suspensions have been showed to vary by sociodemographic characteristics (E. Goodman \& Huang, 2002; Hoff, Laursen, \& Tardif, 2002; Mendez \& Knoff, 2003; Skiba et al., 2011). Covariates included in the analyses predicting substance use and suspensions at follow-up were child gender (female $=0$, male $=1)$, whether the student was African American $(0=$ non-Black, $1=$ Black), whether the student was Hispanic (Hispanic $=1$, non-Hispanic $=0$ ), whether the family's income was above $\$ 24,000$ per year, and whether the family was headed by only one parent $(1=$ single parent, $0=$ two parent $)$.

\section{Data Analyses}

After examining descriptive statistics and unadjusted associations among study variables, we ran logistic regression models to assess how parenting scales predicted substance use and suspensions at follow-up, controlling for measures of those variables at baseline and covariates. Standardized scores of both child- and parent-report family management scales were used in these models. First, main effects of parenting scales based on different reporters were assessed. Second, models were run that included a test of discrepancies. Based on recommendations by Laird and De Los Reyes (2013) for assessing the effects of discrepancies between child and parent reports, polynomial logistic regression models were examined that included baseline measures of the follow-up outcomes, covariates, main effects for child- and parent-report composite scales, quadratic terms for both child- and parent-report total parenting scales, and an interaction term between child- and parent-report measures. Although we did not have an a prior hypothesis regarding nonlinear effects of either child or parent report of parenting on either outcome variable, the quadratic terms were included to guard against estimates for the effects of interaction terms picking up unspecified nonlinear effects of the component variables. As explained by Ganzach (1997), if either of two independent variables has a relationship with an outcome that increases or decreases across the level of the given variable and the two independent variables are correlated, an interaction term added to a regression equation that only includes linear effects of the component variables will show associations with an outcome, even if no moderation is present. Including the quadratic terms guards against this sort of spurious finding. The interaction term in the models tests for the effect of discrepancies or agreement generally by assessing whether scores from one informant are more or less strongly associated with the outcome based on scores from the other informant. In the words of Laird and De Los Reyes (2013): “The interaction terms provide key tests of informant 
discrepancies by directly testing whether high (or low) scores from one informant are more or less strongly associated with the outcome when scores from the other informant are also high (or low)" (p. 4). Post hoc probing of significant interaction terms (Aiken \& West, 1991) was used to investigate the exact nature of the discrepancy effect.

As noted above, data came from a randomized controlled trial of the Common Sense Parenting (CSP) intervention. One-way ANOVA models indicated that intervention condition was not significantly related to either the child or parent report of positive family management (Child measure: $F(2)=0.34, p=.715$; parent measure: $F(2)=2.00, p=.138$ ). Contingency table analysis also showed that the rates of substance use and suspensions did not differ significantly by condition at either baseline (substance use: $\chi^{2}(2)=1.37, p=.566$; suspensions: $\chi^{2}(2)=4.73, p=.094$ ) or follow-up (substance use: $\chi^{2}(2)=2.25, p=.325$; suspensions: $\left.\chi^{2}(2)=0.09, p=.954\right)$. We also tested for interactions between experimental conditions and parenting variables with respect to prediction of substance use and suspensions to see if relationships between parenting and outcome behaviors differed across conditions. We added interaction terms between the positive family management measures and dummy codes for experimental condition to the final logistic regression models reported below. For neither the model predicting substance use nor the models predicting suspensions was the fit of the models significantly better with the interaction terms (model predicting substance use: $\delta \chi^{2}(4)=4.26, p=.372$; model predicting suspensions: $\delta \chi^{2}(4)=1.78, p=$. 776). On the basis of the results of these analyses, we used families from all three conditions in the analyses and omitted the intervention condition as a covariate from the models. More information on the interventions and the results of comparisons between conditions at follow-up can be found in Mason et al. (in press).

\section{Results}

\section{Child- and Parent-Report Measures of Parenting}

Parents gave more positive answers to questions about their parenting than did their children $\left(M_{\text {parent }}=4.02, S D=0.45\right.$ vs. $\left.M_{\text {child }}=3.69, S D=0.58, t(320)=9.60, p<.001\right)$, and child and parent reports of family management were moderately correlated $(r=.29, p<.001)$. Differences in family management scale means by whether students reported substance use and suspensions are shown in Table 1. Both child- and parent-report measures of positive family management were related to substance use at baseline and follow-up. Parent report, but not child report, of family management was significantly related to suspensions at baseline and follow-up. The overlap between substance use and suspensions and the relationship between baseline and follow-up measures of these outcomes are shown at the bottom of Table 1. Children who reported substance use at baseline were more likely to report suspension at both baseline and follow-up. Suspension at baseline, however, was not significantly associated with substance use at follow-up.

\section{Multivariate Logistic Regression Models}

Estimates from models examining the unique effects of child and parent report of family management on substance use and suspensions at follow-up are shown in Table 2. The main effects model predicting substance use revealed that child report, but not parent report, 
predicted substance use. In the models with quadratic and interaction terms, there were significant main effects of child report of positive family management (better parenting predicting less likelihood of substance use), an effect of child report squared (suggesting a diminished protective effect as child-report scores got higher), and an interaction between parent and child report. The interaction between parent and child report reflects the effect of discrepancies in reports of family management practices, over and above main effects of the component variables. To illustrate, when parent report was above the mean, the estimated effect of child-report positive family management on follow-up substance use was negative and statistically significant $(A O R=.16, p<.05)$, controlling for substance use at baseline and other covariates. When parent report was below the mean, the estimated effect of child report of positive family management was weaker and not statistically significant $(A O R=$ $1.22, p=.46$ ), suggesting that agreement in child- and parent-report measures of better family management practices had a protective effect while lack of agreement when children reported positive family management increased the likelihood of substance use. The interaction is graphed in Figure 1. This figure illustrates that the discrepancy effect occurs when child report of parenting is relatively positive but parent report is negative. In that combination, the protective effect of child-reported positive family management is erased. Conversely, if children and their parents agree that parents have positive family management practices, the likelihood of substance use is low, pointing to the protective effect of agreement when both reports of parenting are positive.

The estimates for the main effects model predicting suspensions indicate that parent report of positive family management was a unique predictor of suspensions at follow-up. In the second model, neither the effects of quadratic nor interaction terms were statistically significant.

The models shown in Table 2 also estimate the unique effects of suspensions on substance use and substance use on suspensions. Not surprisingly, given the pattern of bivariate relationships, the effect of suspension on later substance use was nonsignificant after adjusting for early substance use, parenting measures, and other covariates. Substance use at baseline did significantly predict later suspensions in the multivariate model, with substance use at baseline predicting greater likelihood of suspensions at follow-up. Other covariates that uniquely predicted higher likelihood of suspension included students being African American or male, while none of the sociodemographic covariates significantly predicted substance use.

\section{Discussion}

The results of this study suggest that relationships between measures of parenting and adolescent problem behavior outcomes are not uniform across reporters or across behaviors, and that, in some cases, the discrepancies between child and parent report may be important. Both parent and child report of overall better family management practices had unadjusted associations with less substance use, but only child report predicted substance use when both measures were considered together and use at baseline was controlled. Yet parent report was not irrelevant. We found evidence that when children gave a positive assessment of parenting but parents gave a negative assessment, the protective association between the child report 
and likelihood of use was lessened. For suspensions, parent report of family management was a significant predictor in both bivariate and multivariate models, and we found no effect of discrepancies.

The findings for substance use support the hypothesis that child report might be more relevant for a behavior that is covert and happens without the parent knowing about it. Some of the items in the family management measure reflect the nature of interactions between parents and children and do not solely reflect parent behavior. These components of family management, which may be tied to child disclosure (Kerr et al., 2010), may be particularly relevant to covert behaviors such as substance use, and this association may be even stronger due to shared method variance since our measure of substance was based on child selfreport. These findings contrast with the findings from Pasch and colleagues (2010) who found that parent report of parental monitoring was a unique predictor of early adolescent alcohol use while child report was not. In our study we used a broader measure of substance use, which may account for this difference in findings. However, we speculate that when early adolescent substance use is covert, child report of parenting might be a better predictor because the child's negative assessment of family management may be tied to their knowledge of a range of behaviors of which parents are unaware.

There has been little prior research on the relationship between parenting and school suspensions. In the current study, which took place in high-poverty middle schools, a quarter of the eighth-grade students in the sample had experienced a suspension in the year prior to baseline, and almost a fifth of the sample was suspended between baseline and the 6-month follow-up. As has been documented elsewhere (Mendez \& Knoff, 2003; Skiba et al., 2011), African American and male students were particularly likely to be suspended. Substance use also increased the likelihood of suspension. With regard to parenting, parent report, but not child report, was a salient predictor of suspension. We speculate that parent report may be more closely related to the problem behaviors that are overt and for which children are more likely to get caught and experience suspensions, since parent report of family management better reflects the efforts parents have made to respond to a child who acts out and gets in trouble. Parent report may signal, better than child report, how parents are attending to and struggling to manage oppositional and overt forms of antisocial behavior.

The findings from these models with respect to child-parent discrepancies provide some support for child and parent report of parenting practices being an instance of Diverging Operations (De Los Reyes and colleagues (2013)), where meaningful signal comes from both reporters and the degree of disagreement may also be meaningful. In terms of independent, main effects, both child and parent report of family management predicted outcomes, although report saliency differed across the two outcomes we examined in this study. There was also some support for Diverging Operations based on the finding that, when children reported positive family management practices, the effect was not protective when parents reported negative family management practices. This finding is similar to those reported in prior research (De Los Reyes et al., 2010; Reynolds et al., 2011) that protective associations between measures of parenting and adolescent problem behavior are strongest when parents and their children agree that parents are using more positive and less negative parenting strategies. This finding suggests that disagreement may be an indicator of 
underlying dysfunction in the relationship (K. L. Goodman et al., 2010) that is tied to the etiology of early substance use.

\section{Limitations}

This study relied on broad measures of parenting and did not distinguishing between different dimensions of parenting. This limitation was partly due to the use of the short form of the APQ since the subscales, particularly for child report, had low internal consistency (as < .6). As noted by De Los Reyes and colleagues (2013), testing for Divergent Operations requires use of both child and parent measures with acceptable internal consistency. Here, even the internal consistency of broader parenting measures $(\alpha=.62$ for both child- and parent-report measures based on subscale scores as the scale components) was low. It would have been preferable to have more extensive measures of parental monitoring, parental knowledge, and child disclosure so as to build off the work of Kerr et al. (Kerr \& Stattin, 2000; Kerr et al., 2010). Another limitation of the measures was that we relied on self-report of both substance use and suspensions. As noted above, this could have contributed to finding the unique association between child-reported family management and childreported substance use, with children who admitted to substance use being more likely to also report negatively on the parents' family management practices. Further, we have speculated that the different findings for substance use and suspensions may be related to the degree to which these outcomes are covert and hidden from parents, but we did not have direct measures of the extent to which this is so. Our speculation relies on the assumptions that parents often did not find out about early adolescent substance use and that parents did find out when their children were suspended from school. Finally, the generality of the findings is limited by the community sample taking part in an evaluation of a preventive intervention. Using data on a sample of students from high-poverty schools allowed us to examine suspensions as an outcome, since the prevalence rates for suspensions in these schools were quite high. While a majority of those eligible to participate in the project chose not to do so, the students in the sample were similar to the overall populations of the public schools from which they were recruited in terms of sociodemographic characteristics. Although a majority of the families were low income, we found that, even within this sample, sociodemographic variables predicted school suspensions.

\section{Conclusion}

The findings from this study corroborate earlier work that points to the importance of parenting with respect to substance use and support the promise of programs or practices that promote effective parenting strategies. Indeed, parenting factors, such as supervision and discipline, are components of the parenting interventions being tested in the current prevention trial. Intervention effects on substance use and suspensions over the short time span from baseline to follow-up were not found; however, such evidence of effects may emerge as adolescents in the sample move into peak periods of risk during high school. Subsequent analyses based on longer term follow-up data will test this hypothesis. The results here suggest that successful interventions may need to change parenting and family dynamics in a way that affects child perception of these constructs as well as parent-child agreement that parenting practices are positive. While prior studies on parenting have focused on delinquent behaviors, including substance use, here we also examined 
relationships with school suspensions. We found prediction of suspensions in parent reports of parenting, pointing to the potential of reducing behaviors that result in suspensions by working with parents to improve their parenting skills. Finally, the findings point to the complexity of child and parent perceptions of family dynamics. Parents and children have their own unique perspectives, and the degree of agreement, over and above levels reported by either reporter, may be protective for some behaviors.

\section{Acknowledgments}

The project described was supported by National Institute on Drug Abuse Grant \#1R01DA025651. The content is solely the responsibility of the authors and does not necessarily represent the official views of the funding agency or the National Institutes of Health.

\section{References}

Aiken, LS.; West, SG. Multiple regression: Testing and interpreting interactions. Thousand Oaks, CA: Sage; 1991.

Baumrind D. The influence of parenting style on adolescent competence and substance use. Journal of Early Adolescence. 1991; 11:56-95.

Burke, RV.; Schuchmann, LF.; Barnes, BA. Common Sense Parenting: Trainer guide. 3. Boys Town, NE: Boys Town Press; 2006.

Catalano, RF.; Hawkins, JD. The social development model: A theory of antisocial behavior. In: Hawkins, JD., editor. Delinquency and crime: Current theories. New York: Cambridge University Press; 1996. p. 149-197.

De Los Reyes A, Goodman KL, Kliewer W, Reid-Quinones K. The longitudinal consistency of mother and child reporting discrepancies of parental monitoring and their ability to predict child delinquent behaviors two years later. Journal of Youth and Adolescence. 2010; 39:1417-1430. [PubMed: 20020188]

De Los Reyes A, Thomas SA, Goodman KL, Kundey SM. Principles underlying the use of multiple informants' reports. Annual Review of Clinical Psychology. 2013; 9:123-149.

Elgar FJ, Waschbusch DA, Dadds MR, Sigvaldason N. Development and validation of a short form of the Alabama Parenting Questionnaire. Journal of Child and Family Studies. 2007; 16:243-259.

Fleming CB, Mason WA, Haggerty KP, Thompson RW, Fernandez K, Casey-Goldstein M, Oats RG. Predictors of participation in parenting workshops for improving adolescent behavioral and mental health: Results from the Common Sense Parenting trial. Journal of Primary Prevention. (in press).

Fletcher AC, Steinberg L, Williams-Wheeler M. Parental influences on adolescent problem behavior: Revisiting Stattin and Kerr. Child Development. 2004; 75:781-796. [PubMed: 15144486]

Frick PJ, Christian RE, Wootton JM. Age trends in the association between parenting practices and conduct problems. Behavior Modification. 1999; 23:106-128.

Ganzach Y. Misleading interaction and curvilinear terms. Psychological Methods. 1997; 2:235-247.

Goodman E, Huang B. Socioeconomic status, depressive symptoms, and adolescent substance use. Archives of Pediatrics \& Adolescent Medicine. 2002; 156:448-453. [PubMed: 11980549]

Goodman KL, De Los Reyes A, Bradshaw CP. Understanding and using informants' reporting discrepancies of youth victimization: A conceptual model and recommendations for research. Clinical Child and Family Psychology Review. 2010; 13:366-383. [PubMed: 20799062]

Hawkins JD, Catalano RF, Miller JY. Risk and protective factors for alcohol and other drug problems in adolescence and early adulthood: Implications for substance-abuse prevention. Psychological Bulletin. 1992; 112:64-105. [PubMed: 1529040]

Hemphill SA, Heerde JA, Herrenkohl TI, Patton GC, Toumbourou JW, Catalano RF. Risk and protective factors for adolescent substance use in the United States and Australia: A longitudinal study. Journal of Adolescent Health. 2011; 49:312-320. [PubMed: 21856525]

Hill KG, Hawkins JD, Catalano RF, Abbott RD, Guo J. Family influences on the risk of daily smoking initiation. Journal of Adolescent Health. 2005; 37:202-210. [PubMed: 16109339] 
Hoeve M, Dubas JS, Eichelsheim VI, van der Laan PH, Smeenk W, Gerris JRM. The relationship between parenting and delinquency: A meta-analysis. Journal of Abnormal Child Psychology. 2009; 37:749-775. [PubMed: 19263213]

Hoff, E.; Laursen, B.; Tardif, T. Socioeconomic status and parenting. In: Bornstein, MH., editor. Handbook of parenting: Vol. 2: Biology and ecology of parenting. 2. Mahwah, NJ: Lawrence Erlbaum Associates; 2002. p. 231-252.

Jacob T, Windle M. Family assessment: Instrument dimensionality and correspondence across family reporters. Journal of Family Psychology. 1999; 13:339-354.

Keijsers L, Branje SJT, VanderValk IE, Meeus W. Reciprocal effects between parental solicitation, parental control, adolescent disclosure, and adolescent delinquency. Journal of Research on Adolescence. 2010; 20:88-113.

Kerr M, Stattin H. What parents know, how they know it, and several forms of adolescent adjustment: Further support for a reinterpretation of monitoring. Developmental Psychology. 2000; 36:366380. [PubMed: 10830980]

Kerr M, Stattin Hk, Burk WJ. A reinterpretation of parental monitoring in longitudinal perspective. Journal of Research on Adolescence. 2010; 20:39-64.

Kosterman R, Hawkins JD, Guo J, Catalano RF, Abbott RD. The dynamics of alcohol and marijuana initiation: Patterns and predictors of first use in adolescence. American Journal of Public Health. 2000; 90:360-366. [PubMed: 10705852]

Laird RD, De Los Reyes A. Testing informant discrepancies as predictors of early adolescent psychopathology: Why difference scores cannot tell you what you want to know and how polynomial regression may. Journal of Abnormal Child Psychology. 2013; 41:1-14. [PubMed: 22773360]

Laird RD, Marrero MD, Sentse M. Revisiting parental monitoring: Evidence that parental solicitation can be effective when needed most. Journal of Youth and Adolescence. 2010; 39:1431-1441. [PubMed: 19763801]

Loeber R, Schmaling K. Empirical evidence for overt and covert patterns of antisocial conduct problems: A metaanalysis. Journal of Abnormal Child Psychology. 1985; 13:337-353. [PubMed: 4008760]

Losen, DJ.; Skiba, RJ. Suspended education: Urban middle schools in crisis. Los Angeles, CA: The Civil Rights Project; 2010.

Mason WA, Fleming CB, Ringle JL, Thompson RW, Haggerty KP, Snyder JJ. Reducing risks for problem behaviors during the high school transition: Proximal outcomes in the Common Sense Parenting trial. Journal of Child and Family Studies. (in press).

Mason WA, Windle M. Family, religious, school and peer influences on adolescent alcohol use: A longitudinal study. Journal of Studies on Alcohol. 2001; 62:44-53. [PubMed: 11271963]

Mendez LMR, Knoff HM. Who gets suspended from school and why: A demographic analysis of schools and disciplinary infractions in a large school district. Education and Treatment of Children. 2003; 26:30-51.

Morleo M, Cook PA, Elliott G, Phillips-Howard PA. Parental knowledge of alcohol consumption: A cross sectional survey of 11-17 year old schoolchildren and their parents. BMC Public Health. 2013; 13:412. [PubMed: 23631701]

Pasch KE, Stigler MH, Perry CL, Komro KA. Parents' and children's self-report of parenting factors: How much do they agree and which is more strongly associated with early adolescent alcohol use? Health Education Journal. 2010; 69:31-42. [PubMed: 20563227]

Patterson GR, DeBaryshe BD, Ramsey E. A developmental perspective on antisocial behavior. American Psychologist. 1989; 44:329-335. [PubMed: 2653143]

Reynolds EK, MacPherson L, Matusiewicz AK, Schreiber WM, Lejuez CW. Discrepancy between mother and child reports of parental knowledge and the relation to risk behavior engagement. Journal of Clinical Child \& Adolescent Psychology. 2011; 40:67-79. [PubMed: 21229444]

Shelton KK, Frick PJ, Wootton J. Assessment of parenting practices in families of elementary schoolage children. Journal of Clinical Child Psychology. 1996; 25:317-329. 
Skiba RJ, Horner RH, Chung CG, Karega Rausch M, May SL, Tobin T. Race is not neutral: A national investigation of African American and Latino disproportionality in school discipline. School Psychology Review. 2011; 40:85-111.

Willoughby T, Hamza CA. A longitudinal examination of the bidirectional associations among perceived parenting behaviors, adolescent disclosure and problem behavior across the high school years. Journal of Youth and Adolescence. 2010; 40:463-478. [PubMed: 20602155]

Wolf MM. Achievement Place: The teaching-family model. Child Care Quarterly. 1976; 5:92-103. 


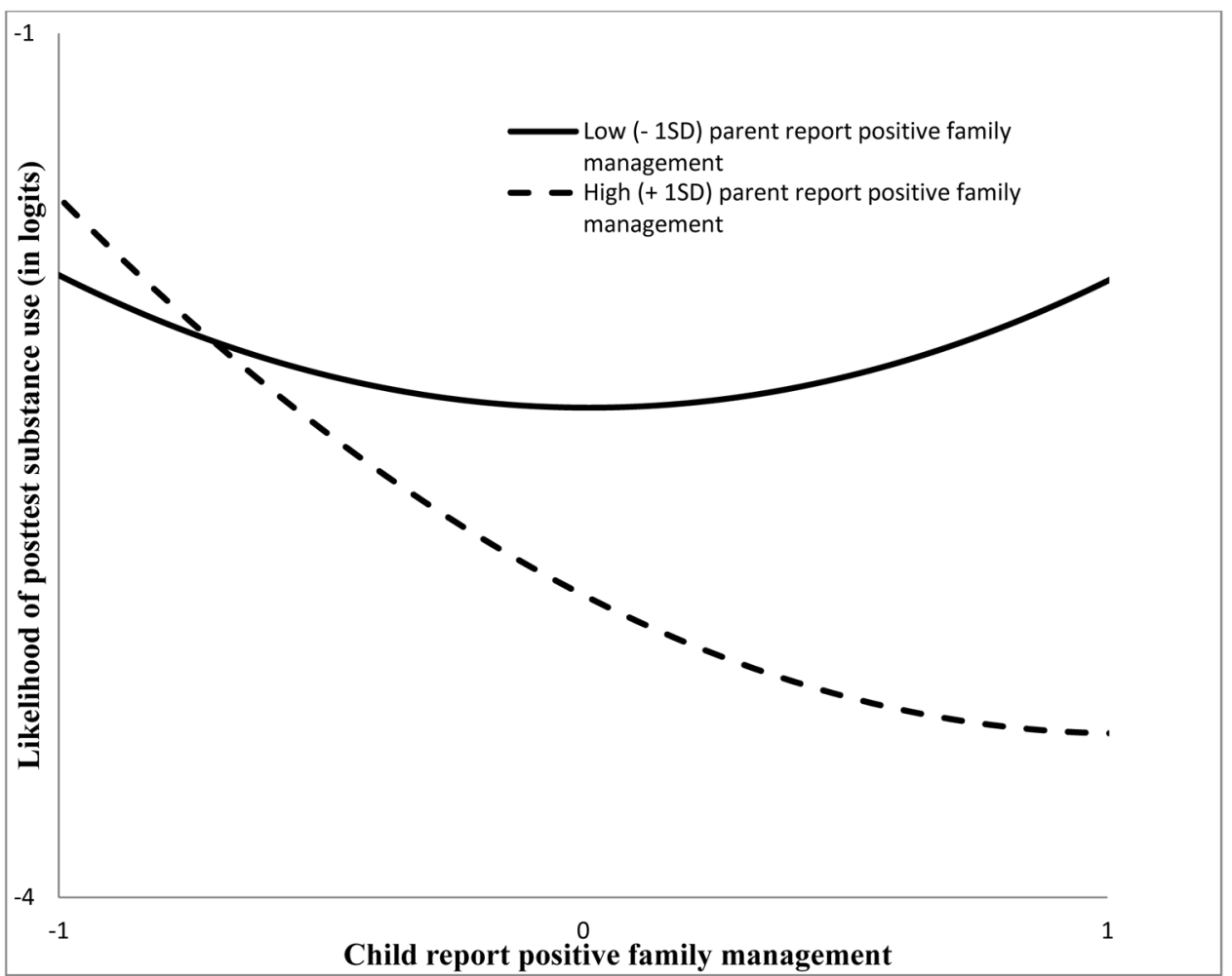

Figure 1.

The likelihood of substance use at follow-up by child-report positive family management by whether parent report of positive family management was negative ( $-1 \mathrm{SD}$ on parent-report scale) or positive (+ $1 \mathrm{SD}$ on parent-report scale). All covariates at their mean values. 
Fleming et al.

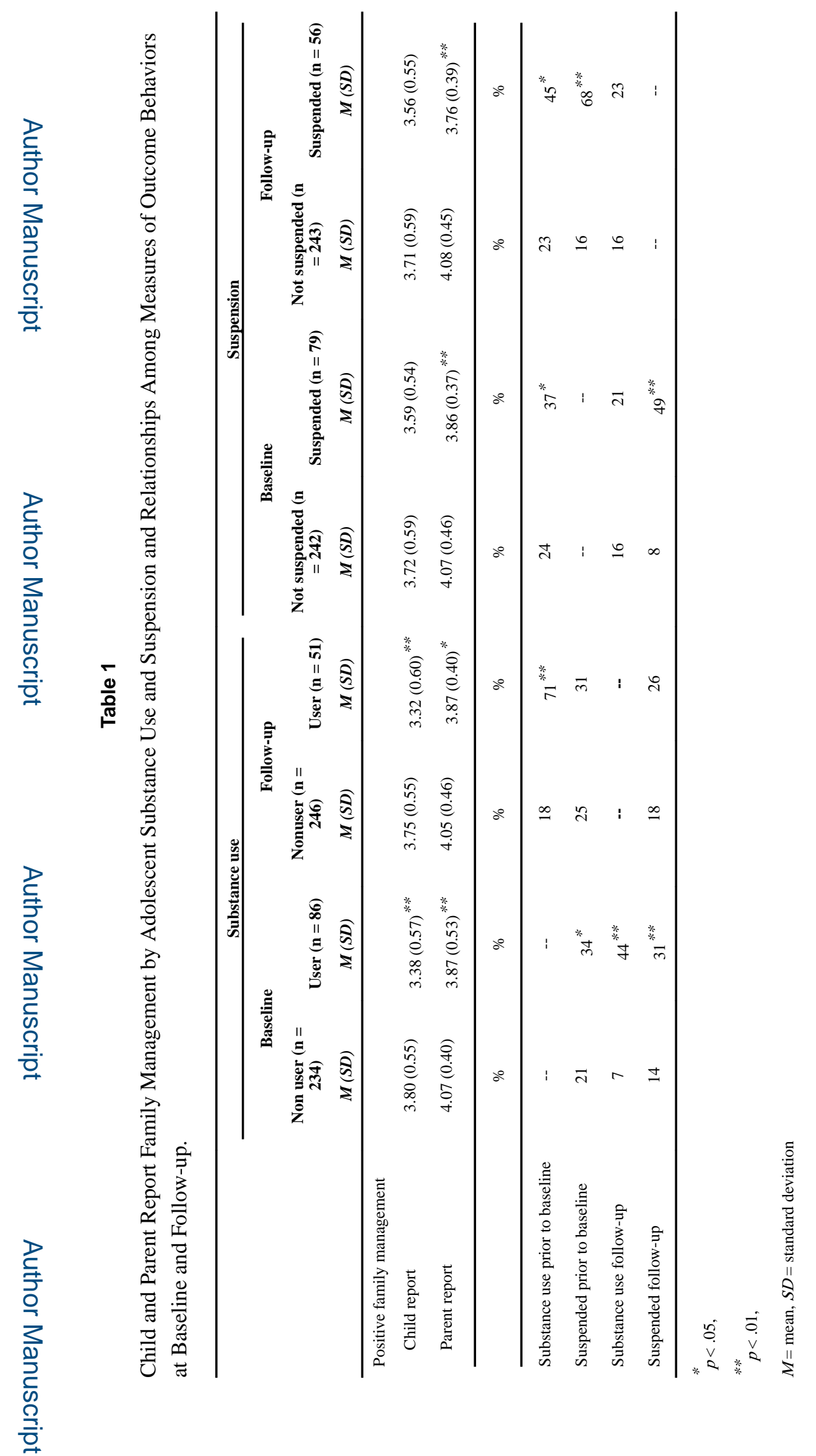

J Early Adolesc. Author manuscript; available in PMC 2017 June 01. 


\section{롤 \\ 골}

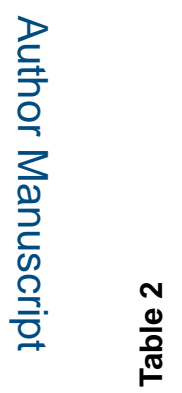

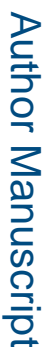

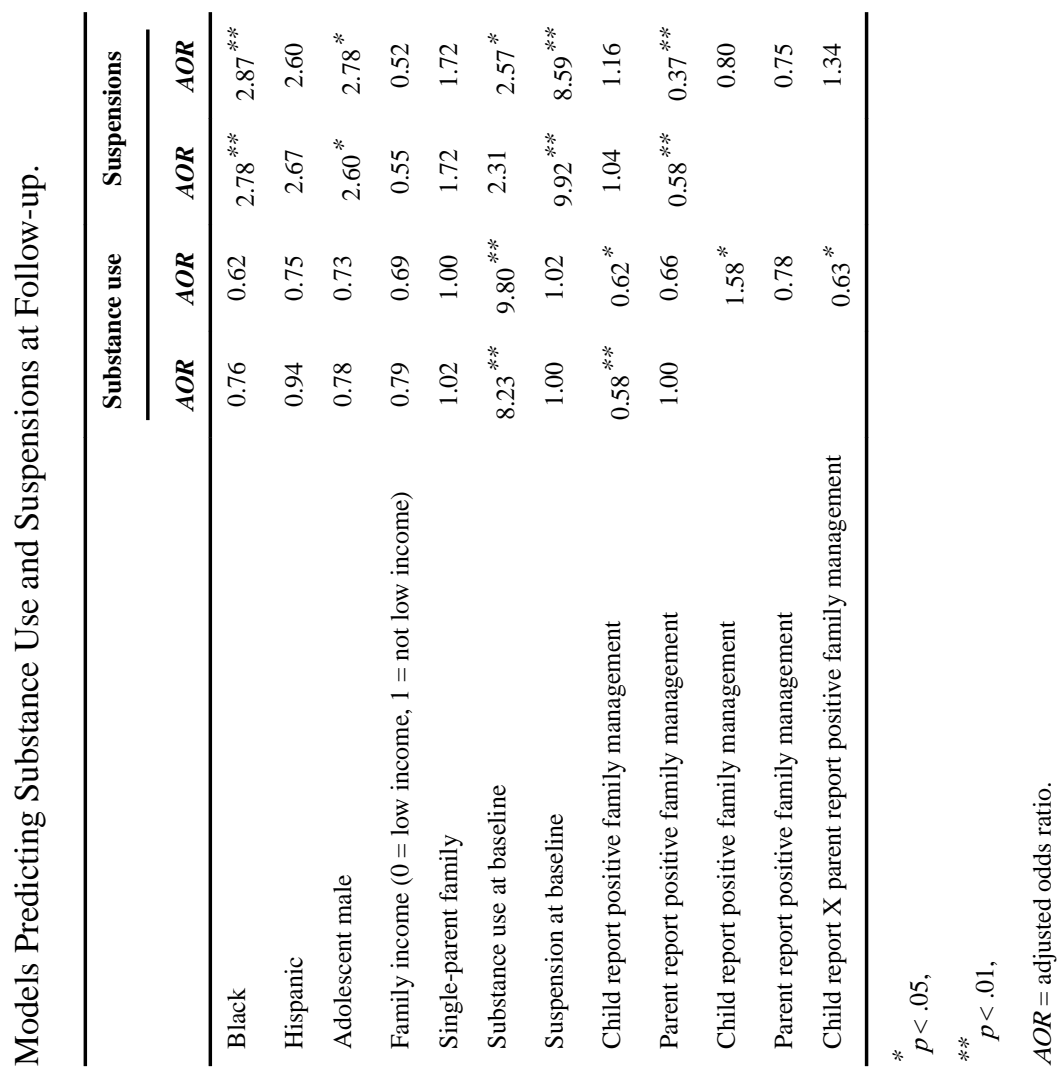

J Early Adolesc. Author manuscript; available in PMC 2017 June 01. 